\title{
TEACHING GLOBAL MINDSET AND INTERCULTURAL COMPETENCE THROUGH THE FRAMEWORK OF EMOTIONALLY INTELLIGENT LEADERSHIP
}

\begin{abstract}
Alongside the growing emphasis on global education within higher education is a greater focus on global leadership and global citizenship within leadership education. In this application manuscript the authors provide examples and discussion of how they have used the Emotionally Intelligent Leadership model as a framework for teaching leadership courses focused on intercultural competence and global mindset. Two specific courses are highlighted, and the authors provide their reflections and implications for leadership education.
\end{abstract}

\section{Introduction}

There is a growing emphasis within higher education institutions in the United States on global education, engagement, and citizenship (AAC\&U, n.d; McTighe Musil, 2006). Accordingly, there is an opportunity and need for students across all majors to develop global knowledge, social responsibility, and intercultural competence with the aim of graduating students "who understand diverse cultures and the complexities of individual identities in a transnational environment.... [and who are] able to communicate across diverse cultures" (McTighe Musil, 2006, p. 6). Looking to the future and anticipating the impact of further globalization and diversification of societies, development of a global mindset and intercultural competence, along with global leadership knowledge and intercultural capacities, is crucial (Andenoro et al., 2013).

\section{Global Education and Leadership}

Alongside the growing emphasis in higher education on global education is a parallel focus on global leadership and associated outcomes and competencies within the realm of leadership education (Council for the Advancement of Standards in Higher Education, 2019; International Leadership Association, 2009). The Council for the Advancement of Standards' (2019) student learning and development outcomes for student leadership programs include the domain of humanitarianism and civic engagement, which entails the specific dimensions of global perspective and understanding and appreciating cultural differences. Further, the foundations of leadership competency within the standards includes cross-cultural and global approaches to leadership as core components.

Scholars shaping the field of leadership studies emphasize the importance of global understanding and intercultural competence (Kellerman, 2018; D. C. 
Roberts, 2018). Kellerman (2018) writes, "you cannot be a leader in the twenty-first century, should not be a leader in the twenty-first century, without having some understanding of other people in other places, of other cultures in other countries" (p. 177). Thus, there is a call for leadership educators to focus on "developing quality curricula to address the need for intercultural capacity and globalized perspectives" (Andenoro et al., 2013, p. 26). In considering how leadership educators can help develop such capacities in students, there is an opportunity to use existing leadership models developed for college students to facilitate learning around the areas of global mindset and intercultural competence.

In this application manuscript we describe how emotionally intelligent leadership (EIL; Shankman, Allen, \& Haber-Curran, 2015) has been used as a framework for leadership courses focused on global mindset and intercultural competence. For the purposes of this manuscript global mindset is understood as "a highly complex cognitive structure characterized by an openness to and articulation of multiple cultural and strategic realities on both global and local levels, and the cognitive ability to mediate and integrate across this multiplicity" (Levy, Taylor, Boyacigiller, \& Beechler, 2007, p. 27) and intercultural competence is defined as the ability to engage in "social interactions in ways that are appropriate to the setting and satisfactory to the interactants, even though interactants do not share the same cultural background as a basis for interpreting the social setting or acting in it" (Jacobson, Sleicher, \& Maureen, 1999, p. 470).

We have each developed curriculum on topics of global mindset and intercultural competence at our institutions and used EIL as a guiding framework for the courses. We found EIL to be an inviting and flexible framework for designing leadership curriculum and also received feedback from students that they resonated with the model. It is our aim in this paper to present a brief overview of EIL, describe two application examples of its use in curricular contexts to teach global mindset and intercultural competence, and suggest implications and recommendations to inform leadership education.

\section{Emotionally Intelligent Leadership}

Emotionally intelligent leadership was first introduced in 2009 as a process-oriented leadership model integrating key concepts of emotional intelligence and leadership (Shankman et al., 2015). The EIL model approaches leadership as a dynamic process encompassing the individual, group, and larger context. Integral to the model is the notion of sense making, or seeking to better understand unknown situations and environments at individual, group, and contextual levels (Haber-Curran \& Shankman, 2018), making EIL a useful framework for approaching leadership education with a focus on intercultural competence and global mindset. A fundamental assumption of the model is that EIL can be learned and developed over time with intentional practice.

The EIL model includes three key facets: consciousness of self, consciousness of others, and consciousness of context, which are defined in Table 1.

The model also includes 19 capacities of EIL that each fall under one of the three facets. This manuscript focuses on how the three EIL facets as broad learning concepts were used in two different courses, and the specific capacities of the model are not directly relevant to the application examples in the manuscript. Readers are encouraged to refer to additional resources focused on EIL for more information about the model and the specific EIL capacities (e.g., Haber-Curran \& Shankman, 2018; Shankman et al., 2015). 
Table 1

Emotionally Intelligent Leadership Facets

\begin{tabular}{|c|c|}
\hline EIL Facet & Facet Components \\
\hline Consciousness of Self & $\begin{array}{l}\text { - awareness of your abilities, emotions, and perceptions } \\
\text { - prioritizing the inner work of reflection and introspection } \\
\text { appreciating that self awareness is a continual and ongoing } \\
\text { process }\end{array}$ \\
\hline Consciousness of Others & $\begin{array}{l}\text { - awareness of the abilities, emotions, and perceptions of } \\
\text { others } \\
\text { intentionally working with and influencing individuals and } \\
\text { groups to bring about positive change }\end{array}$ \\
\hline Consciousness of Context & $\begin{array}{l}\text { - } \quad \text { awareness of the setting and situation } \\
\text { group dynamics affect the process of leadership }\end{array}$ \\
\hline
\end{tabular}

Leadership in a Global Society in an American Leadership Studies Context

The context of my work is an undergraduate leadership studies certificate program at a large state university in the Southeast region of the United States. I am a faculty member in an academic department that offers a 15-credit hour certificate in leadership studies. The program emphasizes foundational theories of leadership, ethics in leadership, gender and leadership, and leadership in global and cultural spaces. My role as a faculty member encompasses guiding students toward understanding leadership as a culturally and socially mediated practice. In my teaching practice I aim to help students understand how their positionality (and complexities of their cultural identities and spaces) influences how they conceptualize and practice leadership.

In Fall 2017 I redesigned and taught a course titled Leadership in a Global Society, a required course for the certificate. The purpose of the course was to examine leadership through a multidisciplinary and global lens, with a focus on culture and its various components and intersections. Students explored the connection between culture and the study and practice of leadership, analyzed what constitutes effective leadership across cultures, as well as collectively and individually identified the knowledge, skills, awareness, and attitudes crucial to leading in cross-cultural situations. As a leadership educator, I carefully reflected on what I wanted students to learn about leadership in a global society. Influenced by
Deardorff (2006), Chin and Trimble (2015), and Bennett and Bennett's (2004) work, the aims of the course were for students to: a) develop a global mindset, b) work towards developing intercultural competence, and c) understand that their positionality influenced how and what they think about leadership and how they engage with others in the leadership process.

Course Focus and Assignment Spotlight. When redesigning the course, my goal was to introduce theoretical perspectives that aligned with the learning goals. Noting that the students varied in terms of past coursework on leadership and interest in the subject, I was keen on finding a theoretical framework that would be accessible to the students and easily relatable and/or transferrable as they catalogued their experiences within the course topic and considered how they might apply the information learned in their own personal and professional development. I was introduced to EIL at the Leadership Education Academy (LEA) in 2015. ElL was presented as a framework for student leadership development, and the model struck me as an applicable framework for discussing leadership knowledge, skills, and awareness within the context of leadership in a global society. I used the EIL model both as a guiding lens to facilitate development of a global mindset and as an anchoring framework for an assignment focused on interculturally competent leadership.

The EIL model was an intentional and prominent part of the course. At the beginning of the course, 
I provided an overview of the three facets of EIL (consciousness of self, consciousness of others, and consciousness of context), and the students participated in guided discussions that connected EIL to the concept and practice of leadership in a global society. By beginning the course with an understanding of EIL, students were primed to carefully and critically consider experiences outside of their own as they encountered course content. For each module, students returned to the EIL model to reflect on their ability to enact the three facets of EIL. At the end of the course, students completed an interculturally competent leadership assignment, which prompted them to create a "new person" using specific cultural and social identifiers and use EIL to discuss this new person's lived experiences and how they (the students) might effectively and appropriately lead this individual given their own experiences. The new personas created were vastly different from the students in the course and from individuals with whom they had interacted in real life. This difference functioned in two ways: it allowed the students to think about what made their own experiences different from this new persona they created (consciousness of self), and the students also considered the possible lived experiences of the persona they created. The assignment included detailed research on communities in the United States and around the world and the issues faced by the communities (consciousness of others). Last, students discussed the particular leadership knowledge, skills, and awareness (elements of intercultural competence) they would need to use and/or develop to effectively and appropriately lead this new person (consciousness of context).

Outcomes and Instructor Reflection. A combination of research and critical reflection, the interculturally competent leadership assignment allowed students to consider the three facets of EIL. The concept of intercultural competence stresses the value of experiences over time (Deardorff, 2018), and although there was limited time within the confines of the semester course structure, EIL enabled students to work on a short-term assignment while thinking about their long-term goals in order to help them develop the necessary knowledge, skills, and awareness to lead in a global society. In a class debrief session, students noted the assignment was challenging in ways that made them consider and reconsider their own positionality and how they navigate different spaces. Further, some students acknowledged and shared the limits of their knowledge and experiences, noting that they had little to no experience with interacting with people from different backgrounds. Other students identified the interculturally competent leadership assignment as one of the most meaningful assignments they had completed, which underscores the deep learning this assignment prompted and facilitated

In reflecting on students' experiences, I can see why some viewed the assignment as challenging. I take this as a positive element of the assignment because it required the students to engage in emotional and intellectual labor to think about people, places, things, and events that were not part of their quotidian experiences. Furthermore, doing this kind of work in a short amount of time may have presented a challenge in allowing for individual critical reflection and processing. In reading and evaluating students' papers, I also considered how I would have approached the assignment. The grading process revealed to me that $\mathrm{I}$, as an international faculty member from Zimbabwe, had a lot to learn about: a) communities in the United States and their histories, and b) the limits of my own knowledge and areas of development when it comes to my pursuit of intercultural competence.

Using the EIL model in framing language and content for developing a global mindset, intercultural competence, and reflective practices for leadership in a global society resulted in a rich learning experience for the students and for me as an educator. In Teaching to Transgress, bell hooks (1994) counseled that educators cannot ask students to do deep and critical self-reflection if they themselves are not willing and able to also do so. In designing the assignment, I thought deeply about the language I was using for the cultural and social identifiers (and 
thus, the limits of my own knowledge). Even though the students were writing about a fictitious person, the identifiers I used in the assignment (e.g., gender, race, socio-economic status, education, language use, citizenship) represented real communities and by extension, experiences and challenges. For example, I debated about whether I should use the term Latinx or Latina/Latino. This required me to do my own research and learn about the discourse and politics of the terms I chose and used. I also thought about using the identifier Asian. From a global perspective, it is impossible to generalize this identifier because the continent itself presents different countries, cultures, ethnicities, languages, histories, and traditions. When used within the context of the United States, the identifier presents a racial category that diminishes the nuances previously noted. I guided the students through the descriptors used because they were not familiar with some of the terms or the context of the terms, and it was important for me to eschew reinforcement of assumptions, single stories, and lack of knowledge or awareness that come with how particular identifiers are perceived. This reflection helped me to use the three facets of the EIL model to consider: a) what do I know about this (consciousness of self)?, b) how might others experience this phenomenon (consciousness of others)?, and c) what are the gaps in my knowledge and how do these gaps impact this assignment and my teaching (consciousness of context)?

Through a recent process of curriculum design, the course was redesigned to be two separate courses: Leadership and Intercultural Competence (general education course/leadership studies elective) and Leadership and Global Issues (upper-level course/ certificate requirement). The assignment is a natural fit for each of the new courses because it is a powerful approach for guiding students through the necessary self-reflective process of articulating the knowledge, skills, and awareness that are imperative for leading in ways that recognize and prioritize different lived experiences, leadership and followership contexts, and the impact of social and cultural identities. EIL offered a way for students to reflect on their capacity for leadership in a global society. I am hopeful the students will continue to use the model to assess their leadership experiences.

\section{Intercultural Competence in an Austrian Business Context}

In Spring 2018 I taught two sections of Intercultural Competence, a required course in the business management master's program at Salzburg University of Applied Sciences in Austria as a visiting professor. The course included 24 instructional hours and was taken in students' second semester. Approximately 15 students were enrolled in each section. I am American, and I taught in English. The students in the courses all spoke German as their first language and came from either Austria or Germany. They were each proficient in English and were required to pass an English language exam in order to enroll in the program.

The purpose of the course was to prepare students to lead and manage in global and multicultural contexts with a focus on interpersonal and intrapersonal dimensions of intercultural competence. Curriculum and course assignments were designed to help students learn about cultural frameworks and value dimensions; learn about multicultural teams; and explore their own world views, perspectives, and cultural backgrounds, with the ultimate goal of preparing students to work in and lead teams with people from different backgrounds and effectively adapt to other cultures.

Course Curriculum and Assignments. As I developed the course I used three key frameworks related to intercultural competence: (a) Livermore's (2015) cultural intelligence model, (b) Deardorff's (2006) model of intercultural competence, and (c) Molinsky's (2013) concept of global dexterity. Each offers a different perspective and approach to developing knowledge, skills, and abilities related to intercultural competence. The frameworks also emphasize the importance of having an awareness of oneself and one's own culture, awareness of others and their cultural frameworks, and awareness of the larger cross-cultural context, which directly aligns with the 
three facets of EIL (Shankman et al., 2015). Thus, I used EIL as a conceptual framework to design the course to facilitate the development of greater consciousness of self, others, and context.

In designing the course, it became clear that consciousness of context naturally fit as an overarching umbrella for a course on intercultural competence, as the concept of culture is inherently about a larger context. Additionally, the various topics covered in the course provided an opportunity for students to learn about culture and intercultural competence in relation to themselves (consciousness of self) and in relation to others (consciousness of others). Examples of these topics include:

- Worldview and mental models

- Cultural value dimensions

- Dimensions of social identity

- $\quad$ Ethnocentrism and stereotyping

- Multicultural groups and teams

- Cross-cultural communication
Thus, the class sessions focused on how course topics related to the students as individuals and business leaders as well as how the topics related to understanding and leading others, seamlessly reflecting the three facets of EIL.

Each graded component clearly connected to at least one of the EIL facets. Table 2 provides an overview of the course assignments with a brief description of each assignment and the EIL facet(s) related to each assignment. I intentionally designed the first and last assignments to focus on consciousness of self in order for students to begin by reflecting on their own cultural values, traditions, and practices and end by assessing their intercultural competence and developing an action plan for continued growth.

Table 2

Course Assignments and EIL Connections

\begin{tabular}{|c|c|c|}
\hline Assignment & Description & EIL Facet Connection \\
\hline $\begin{array}{l}\text { Cultural Self-Reflection } \\
\text { Paper }\end{array}$ & $\begin{array}{l}\text { Explore one's own cultural values, } \\
\text { traditions, and practices; Discuss } \\
\text { experiences working with people } \\
\text { from other cultures }\end{array}$ & $\begin{array}{l}\text { Self } \\
\text { Context }\end{array}$ \\
\hline $\begin{array}{l}\text { Cultural Dimensions } \\
\text { Presentation }\end{array}$ & $\begin{array}{l}\text { Group presentation exploring } \\
\text { cultural values \& dimensions of } \\
\text { another country }\end{array}$ & $\begin{array}{l}\text { Others } \\
\text { Context }\end{array}$ \\
\hline $\begin{array}{l}\text { Global \& Multicultural } \\
\text { Teams Interview }\end{array}$ & $\begin{array}{l}\text { Interview professional who has } \\
\text { been part of or led a global or } \\
\text { multicultural team }\end{array}$ & $\begin{array}{l}\text { Others } \\
\text { Context }\end{array}$ \\
\hline Guest Speaker & $\begin{array}{l}\text { Discussion with a guest speaker on } \\
\text { leading an international team in } \\
\text { Qatar with a focus on lessons } \\
\text { learned and cultural intelligence }\end{array}$ & $\begin{array}{l}\text { Others } \\
\text { Context }\end{array}$ \\
\hline Cultural Pairing & $\begin{array}{l}\text { One-on-one video chat with a } \\
\text { graduate student in the United } \\
\text { States to discuss cultural values } \\
\text { and differences }\end{array}$ & $\begin{array}{l}\text { Self } \\
\text { Others } \\
\text { Context }\end{array}$ \\
\hline $\begin{array}{l}\text { Cultural Self-Assessment } \\
\text { \& Action Plan }\end{array}$ & $\begin{array}{l}\text { Complete self-assessment tools on } \\
\text { cultural intelligence/intercultural } \\
\text { competence, assess competencies, } \\
\text { and develop action plan }\end{array}$ & Self \\
\hline
\end{tabular}


Although I used EIL as the conceptual framework for the course, I purposefully did not introduce the EIL model until the last class session when wrapping up the course. After teaching a short lesson on EIL, students engaged in an activity in which they mapped the course content and their learning across the three EIL facets. Students could clearly see the connection between their learning and the EIL model, and they seemed to resonate with EIL as a meaningful way to synthesize their learning. Introducing EIL at the end of the course also primed the students for the subsequent two semesters in which they would be taking two courses focused on emotional intelligence and social skills framed in part by the EIL model.

Instructor Reflection. With a background in teaching in leadership and education departments, I had not previously taught a course focused specifically on intercultural competence, nor had I taught in a business department. I had a foundational understanding of intercultural competence, but I was not well versed in the scholarly literature on the topic. As I delved into the literature, it was clear that the three levels of self, others, and context were salient, consistent, and often interconnected. These three levels are prevalent in the leadership literature as well, with the EIL framework serving as a model that clearly identifies the levels of self, others, and context with a connection to both leadership and emotional intelligence. Approaching the concept of intercultural competence alongside the EIL model seemed like a clear and natural fit. I have previously found EIL to be an approachable model for students that provides many opportunities for students to connect with the model, learn about leadership conceptually, make meaning of their own experiences, and identify ways to guide their leadership practice.

Using the EIL model to frame the course also helped me make better sense of the intercultural competence literature and the ways topics could be discussed, sequenced, and connected. I intentionally sought to incorporate a focus on self, others, and context and help students understand how these different levels are interconnected and at times even inseparable. As an example, the cultural pairing assignment, in which the students engaged in a video conversation with graduate students in the United States to discuss their cultural values and experiences, served not only to help the students learn about someone from another cultural background (consciousness of others), but also provided an opportunity for the students to see their own cultural background more clearly (consciousness of self).

I would be remiss if I did not also acknowledge how teaching this course, building relationships with the students, and learning from the students through inclass discussions and by reading their assignments was an incredible learning opportunity for me. I was a visiting professor for the semester and chose to come to Austria in part because I was interested in immersing myself in Austrian culture, having only previously visited as a tourist. Teaching a course on intercultural competence with students from another culture and in a different country provided a unique vantage point for gaining a deeper understanding of Austrian culture. As an example, students were asked to bring a cultural artifact (something tangible representing their culture) to share with the class in a brief presentation in the second class session. The activity of sharing cultural artifacts supplemented the students' cultural self-reflection paper, which aimed to help students reflect upon their own cultural values and experiences as a way to help them expand their consciousness of self through a culture lens. The cultural artifact sharing activity allowed for learning about others' cultures, aligned with consciousness of others. Some artifacts shared by students included a photograph of a student's grandmother, homemade Apfelstrudel made from a family recipe, traditional Lederhosen used for cultural events, and a CD from the German folk band of which a student had been a part in his hometown since he was a young boy. Accompanying each artifact was a personal story, and behind each story was a sense of pride. I left the class session with incredible new insights about the culture and a greater understanding of personal connections behind what outsiders might see as typical cultural symbols (e.g., Lederhosen and Apfelstrudel). I was overwhelmed with sincere gratitude of the students' 
willingness to open up and share something so personal.

Teaching this course challenged me to more fully examine my own culture and see myself through a cultural lens. As the students engaged in the process of seeking to gain a better understanding of their cultural background, I was doing the same. I, too, grappled with what to bring as a cultural artifact and how I would share this artifact with the students. I encouraged students to ask me questions about my observations and experiences in Austria (which they often found very entertaining) as well as about my life and experiences in America. Two of the questions that stood out are: "Why do strangers say hi and ask you how you're doing in America?" and "Why do servers bring you the bill at the end of the meal when you're not done eating yet and didn't ask for the check?" I often prompted the students to also share why they asked the questions, as cultural values were often inherent in the questions. Students' questions led to great class discussions on cultural values and differences and also challenged me to more deeply and critically examine my culture and the broader American culture. I encouraged students to approach their learning through a lens of cultural curiosity and cultural humility, and I sought to model this as well. I am thankful for the opportunity to also be a learner alongside the students, and the topic of intercultural competence as framed by the EIL model allowed a fitting setting in which to learn.

\section{Implications and Recommendations}

We each used EIL as a framework to help learners engage the tensions and opportunities that exist across worldviews, experiences, and leadership perspectives. Using the model to guide curriculum design in two courses with related topics demonstrates the versatility of the model within leadership education. Noting the diversity in leadership education and learning environments (e.g., consultancy, government, healthcare, business, higher education), we invite leadership educators to consider how they might integrate EIL in learning activities that promote global mindset and intercultural competence.

As is demonstrated in our reflections and suggested in the conceptual frameworks we used, teaching topics of global mindset and intercultural competence requires leadership educators to closely and frequently examine their own positionality and how it impacts the learning environment. D. L. Roberts (2018) emphasizes the importance of this reflection noting: "We must examine our own privilege and how that relates to, and interacts with, various cultural contexts" (p. 111). The risk of foregoing this process may reinforce destructive behaviors/mindsets that undermine learning goals. It is critical that leadership educators recognize the limits of their own knowledge and understand how their worldviews, cultural orientations, and perspectives manifest in learning spaces.

Although as leadership educators we do not have to be experts in "international citizenship and leadership," we do have a responsibility to "equip ourselves with knowledge of our students, cultural competence, and cultural humility, none of which requires that we have significant, or any for that matter, international travel, study, or work experience" (D. L. Roberts, 2018, p. 110). We strongly advance that leadership educators seek professional development, continuing education, and experiential opportunities that provide tools for understanding theories and frameworks that govern global mindset and intercultural competence, which are antecedents to understanding leadership in global spaces. Without subject knowledge and experience, we risk propagating an incomplete and surface type of inquiry that lacks criticality (e.g., questions and questioning of power, identity, positionality) and misses the inherent complexity of global mindset and intercultural competence. Investing in this kind of self-learning and reflection helps leadership educators to position themselves as learners as well, with the opportunity to reflect on their own consciousness of self, consciousness of others, and consciousness of context (Shankman et al., 2015). 
A final consideration for using EIL as a guiding framework for courses that focus on global mindset and intercultural competence is selecting an appropriate and conducive learning environment. In our two examples, course design included class modality (face-to-face and hybrid). A face-to-face environment enabled us to model and facilitate vulnerability, engage learners in meaningful dialogue, and guide individual and collective reflection. The Leadership in a Global Society course discussed in this manuscript took place in a hybrid setting, offering face-to-face interaction as well as online engagement. The same course has also been taught in a fully online environment, and the interculturally competent leadership assignment was included in the course. Because of the asynchronous virtual environment, the assignment did not seem to be as powerful, particularly because there was no group debrief and reflection that created a space for immediate feedback, discussion, and dialogue. In our examples, a hybrid and face-to-face environment allowed for synchronous, communal, and reciprocal interaction wherein learners could be transparent about their experiences and perspectives; we, as instructors, could be open and vulnerable about our own experiences and perspectives; and we could seek to skillfully navigate and facilitate dialogue and meaning making around the topics.

As Roberts (2018) notes, "our world is in transition" (p. 112). This transition is marked by increasing interconnectedness and engagement with different ways of knowing and being. In the context of leadership education, this presents a crucial "learning moment" in which knowledge of people, places, things, and events is critical. There is an opportunity to integrate intercultural competence and global mindset as essential elements of leadership theories and frameworks (Roberts \& Roberts, 2018), and ultimately, leadership practice; in fact, we argue there is a obligation to do so. As leadership educators it is our responsibility to prepare learners for the reality of living and working in a world in transition (Roberts, 2018). Deardorff's (2018) exhortation carries more urgency: "Learning to navigate successfully across cultural difference is one of the most vital skills for those who strive to provide leadership today" ( $p$. 49), positioning global mindset and intercultural competence as an imperative in leadership education (Roberts, 2018). 


\section{References}

Andenoro, A. C., Allen, S. J., Haber-Curran, P., Jenkins, D. M., Sowcik, M., Dugan, J. P., \& Osteen, L. (2013). National leadership education research agenda 2013-2018: Providing strategic direction for the field of leadership education. Retrieved from Association of Leadership Educators website: http:// leadershipeducators.org/ResearchAgenda

Association of American Colleges and Universities. (n.d.). Global learning. Retrieved from https://www.aacu. org/resources/global-learning

Bennett, J. M., \& Bennett, M. J. (2004). Developing intercultural sensitivity: An integrative approach to global and domestic diversity. In D. Landis, J. Bennett, \& M. Bennett (Eds.), Handbook of intercultural training (3rd ed., pp. 147-165). Thousand Oaks, CA: Sage. doi:10.4135/9781452231129.n6

Chin, J., \& Trimble, J. (2015). Diversity and leadership. Thousand Oaks, CA: Sage.

Council for the Advancement of Standards in Higher Education. (2019). CAS professional standards for higher education (10th ed.). Washington, DC: Author.

Deardorff, D. K. (2006). Identification and assessment of intercultural competence as a student outcome of internationalization. Journal of Studies in International Education, 10(3), 241-266. doi:10.1177/1028315306287002

Deardorff, D. K. (2018). Exploring the significance of culture in leadership. In D. C. Roberts \& D. L. Roberts (Eds.), Cultivating students' capacity for international leadership (New Directions for Student Leadership, vol. 160, pp. 41-51). San Francisco, CA: Jossey-Bass. doi:10.1002/yd.20309

Haber-Curran, P., \& Shankman, M. L. (2018). Emotionally intelligent leadership: An applied model for developing individuals and advancing organizations. In P. Meyer \& H. Gölzner (Eds.), Emotionale Intelligenz in Organisationen - Entwicklung \& Anwendung - Der Schlüssel zum Wissenstransfer zwischen Organisationen \& angewandter Forschung (pp. 213-225). Wiesbaden, Germany: Springer-Gabler Verlag.

hooks, b. (1994). Teaching to transgress. New York, NY: Routledge.

International Leadership Association. (2009). Guiding questions: Guidelines for leadership education programs. Silver Spring, MD: Author. Retrieved from http://www.ila-net.org/Communities/LC/ GuidingQuestionsFinal.pdf

Jacobson, W., Sleicher, D., \& Maureen, B. (1999). Portfolio assessment of intercultural competence. International Journal of Intercultural Relations, 23(3), 467-492. doi:10.1016/S0147-1767(99)00006-1

Kellerman, B. (2018). Professionalizing leadership. New York, NY: Oxford University Press.

Livermore, D. A. (2015). Leading with cultural intelligence: The real secret to success (2nd ed.). New York, NY: AMACOM.

McTighe Musil, C. (2006). Assessing global learning: Matching good intentions with good practice. Washington, DC: Association of American Colleges and Universities. Retrieved from: https://www.aacu. org/sites/default/files/files/publications/Global_Learning2006.pdf 


\section{References}

Molinsky, A. (2013). Global dexterity: How to adapt your behavior across cultures without losing yourself in the process. Boston, MA: Harvard Business Review Press. doi:10.1002/tesj.171

Roberts, D. C. (2018). Our world: International, urbanizing, and driven by connectedness. In D. C. Roberts \& D. L. Roberts (Eds.), Cultivating students' capacity for international leadership (New Directions for Student Leadership, vol. 160, pp. 11-20). San Francisco, CA: Jossey-Bass. doi:10.1002/yd.20306

Roberts, D. C., \& Roberts, D. L. (Eds.). (2018). Cultivating students' capacity for international leadership (New Directions for Student Leadership, vol. 160). San Francisco, CA: Jossey-Bass.

Shankman, M. L., Allen, S. J., \& Haber-Curran, P. (2015). Emotionally intelligent leadership: A guide for students (2nd ed.). San Francisco, CA: Jossey-Bass. 